\title{
Os centros de interesse lidos em manuais do ensino primário: há saberes aritméticos?
}

\author{
Centers of interest read in primary education manuals: is there arithmetic \\ knowledge?
}

\author{
Juliana Chiarini Balbino Fernandes \\ Doutora em Ciências. \\ Universidade Federal de São Paulo - UNIFESP. \\ São Paulo, SP - Brasil. \\ juliana-chiarini@hotmail.com
}

\begin{abstract}
Resumo: O objetivo deste texto é analisar a presença dos saberes aritméticos no manual didático "Os Centros de Interesse na Escola" (1931), escrito por Abner de Moura, a partir das apropriações do ideário de Ovide Decroly. Este trabalho foi norteado pelos estudos desenvolvidos pela Equipe de Pesquisa em História das Ciências da Educação (ERHISE) e estudos de Roger Chartier (1991). O manual, intitulado "Os Centros de Interesse na Escola", apresenta a proposta de Decroly e parte da observação para elaborar um programa síntese: conhecimento pela criança de suas necessidades e conhecimento do ser humano - família, escola e ambiente social, animal e vegetal. Nesta análise, o ensino de matemática não deveria ser limitado ao horário, abrangendo todo aspecto quantitativo que surgiria a partir das demais matérias. O conceito de unidade se estabeleceria na união da observação, associação e expressão, responsável por coordenar o programa de atividades, destinado a uma ideia central.
\end{abstract}

Palavras-chave: saberes aritméticos; manual didático; centros de interesse.

Abstract: The objective of this text is to analyze the presence of arithmetic knowledge in the didactic manual "The Centers of Interest in School" (1931), written by Abner de Moura, based on the appropriations of the ideas of Ovide Decroly. This work was guided by the studies developed by the Research Team in the History of Educational Sciences (ERHISE) and the studies by Roger Chartier (1991). The manual entitled "The Centers of Interest at School" presents Decroly's starts from the observation to elaborate a synthesis program: children's knowledge of their needs and knowledge of the human being - family, school and social, animal and plant environment. In this analysis, the teaching of mathematics should not be limited to time, covering every quantitative aspect that would arise from the other subjects. The concept of unity would be established in the union of observation, association and expression, responsible for coordinating the program of activities, aimed at a central idea.

Keywords: arithmetic knowledge; didactic manual; centers of interest.

Cite como

(ABNT NBR 6023:2018)

FERNANDES, Juliana Chiarini Balbino. Os centros de interesse lidos em manuais do ensino primário: Há saberes aritméticos? Dialogia, São Paulo, n. 38, p. 1-10, e19503, maio/ago. 2021. Disponível em: https://doi.org/10.5585/38.2021.19503.

\section{American Psychological Association (APA)}

Fernandes, J. C. B. (2021, maio/ago.). Os centros de interesse lidos em manuais do ensino primário: Há saberes aritméticos? Dialogia, São Paulo, 38, p. 1-10, e19503. https:// doi.org/10.5585/38.2021.19503. 


\section{Introdução}

Esta pesquisa integra um projeto temático vinculado a Fundação de Amparo à Pesquisa do Estado de São Paulo (FAPESP) intitulado "A matemática na formação de professores e no ensino: processos e dinâmicas de produção de um saber profissional, 1890-1990", coordenado pelo Professor Dr. Wagner Rodrigues Valente. Esse projeto parte de uma interrogação da atualidade para o desenvolvimento de estudos históricos: que matemática deverá formar o futuro professor? As referências teórico-metodológicas utilizadas para o desenvolvimento do projeto, no âmbito do Grupo de Pesquisa de História da Educação Matemática (GHEMAT - Brasil), incluem o debate sobre o ofício de historiador e as leituras dos trabalhos desenvolvidos pela Equipe de Pesquisa em História das Ciências da Educação (ERHISE), da Universidade de Genebra, na Suíça. Esses “[...] referenciais voltam-se para a compreensão histórica dos saberes profissionais da docência, objetivados em termos de legislações, decretos, dentre outros, no que se refere aos saberes a ensinar e os saberes para ensinar" (VALENTE et al., 2017, p. 3).

Perspectivas teóricas, no que tange à formação de professores, envolvem saberes de natureza diferente daqueles aplicados disciplinarmente. Desse modo, “[...] a matemática que integra a formação para a docência, a matemática como uma ferramenta do profissional do ensino tem outro caráter que a matemática de cunho disciplinar, própria da ciência matemática, não comprometida profissionalmente com o seu ensino" (VALENTE et al., 2017, p. 9).

Um dos eixos desse projeto é “A matemática na formação de professores para os primeiros anos escolares: a constituição da matemática para ensinar?". Os estudos desse eixo pesquisam as sistematizações dos saberes envolvidos na orientação das ações docentes; saberes sobre o aluno e suas maneiras de aprender matemática; saberes sobre as práticas de ensino, ou seja, métodos, procedimentos, dispositivos; assim como saberes sobre modalidades de organização e gestão dos saberes matemáticos, planos de estudos e finalidades das diferentes propostas curriculares.

Em específico, um desses estudos dedica-se a investigar a presença da aritmética em meio a uma nova vaga pedagógica: o movimento da Escola Nova e, no âmbito dessa vaga, a pedagogia dos Centros de Interesse. A questão norteadora deste estudo investiga como está configurado o saber aritmético no âmbito de uma pedagogia escolanovista.

Este trabalho busca investigar como ocorreram as apropriações da proposta dos Centros de Interesse que circulou em escala internacional, aportando também no Brasil. Sendo assim, este artigo tem, por objetivo, analisar o manual "Os Centros de Interesse na Escola”, escrito por Abner de Moura, em 1931 sob duas vertentes: apropriações do ideário decrolyano; e saberes aritméticos presentes na proposta didáticos pedagógica Centros de Interesse. 


\section{Considerações teórico-metodológicas}

A discussão sobre a formação de professores envolve, desde os primeiros tempos em que é pensada a sua institucionalização, no início do século XIX, os saberes específicos para a profissão de ensinar. Os estudos desenvolvidos pelo grupo suíço revelam que as dinâmicas de constituição dos saberes específicos para a formação de professores, em nível primário (os primeiros anos escolares) e secundário (os anos escolares compreendidos pós-ensino primário e pré-ensino universitário), ligam-se à compreensão de como se articulam dois tipos de saberes: saberes a ensinar e saberes para ensinar (HOFSTETTER et al., 2009).

O primeiro, saberes a ensinar, relaciona-se aos saberes produzidos pelas disciplinas universitárias e pelos diferentes campos científicos considerados essenciais para a formação dos professores. Enquanto o segundo, saberes para ensinar, relaciona-se à docência e está diretamente ligado àqueles saberes próprios para o exercício da profissão docente. Assim, ambos os saberes se constituem como saberes da formação de professores, mas a expertise profissional, o que caracteriza a profissão de professor é a junção entre a posse dos saberes para ensinar. Entretanto, Hofstetter et al. (2009) apontam que esses saberes estão em articulação com os saberes a ensinar.

Nesse mesmo contexto dos saberes, há a prática da apropriação, que pode ser considerada como prática de transformação de produtos culturais e a construção do sentido por meio de textos escritos, a qual pode ser realizada pelo cruzamento da história das práticas sociais com a história das representações contidas em um mesmo contexto. As representações inscritas nas propostas didáticas pedagógicas Centros de Interesse podem trazer as interpretações que seus elaboradores fizeram das propostas para alcançar os professores, saberes técnicos (saberes para ensinar) que constituem um recurso específico para a história das apropriações (CHARTIER, 1991).

\section{Jean Ovide Decroly e os centros de interesse}

O estudo dos vários métodos, tendendo a vários fins, pode ser chamado de teoria da educação, não pedagogia. “A pedagogia é, a um tempo, conjunto de doutrinas e princípios, visando um programa de ação: dá como fixados os fins, e procura adaptar a esses fins uma técnica educativa determinada" (LOURENÇO FILHO, 1930, p. 118).

Lourenço Filho (1930, p. 121) explica que, na concepção da Escola Nova, há três grandes sistemas de aplicação científica, difundido mundialmente, sendo eles: “[...] o sistema Montessori, o sistema Decroly, e o sistema de projetos, este originado especialmente das ideias educativas de Dewey”. O nascimento do sistema Decroly é semelhante ao do sistema Montessori: “[...] ambos 
nasceram do ensino de crianças anormais, ambos foram criados por médicos especializados em estudos da educação" (LOURENÇO FILHO, 1930, p. 131).

Ovide Decroly, formou-se em medicina pela Faculdade de Medicina de Gand, em 1896. Após um estágio em clínicas de neurologia, Decroly retornou à Bélgica onde foi designado chefe do serviço de crianças "retardadas" e médico inspetor das classes especiais de "anormais", em Bruxelas. Após iniciar os trabalhos como chefe da escola em Bruxelas, aconteceu o despertar para a pedagogia (LOURENÇO FILHO, 1930).

Em 1901, Decroly fundou o Instituto para "retardados" e "anormais", em Uccle, nos arredores da cidade Bruxelas. Em 1907, ocorreram as primeiras aplicações e resultados, em crianças, em Bruxelas (Ixelles) na escola da rua de Ermitage. No período pós-guerra, as autoridades belgas passaram a observar e oficializar as escolas. Em 1922, Decroly foi chamado nos Estados Unidos, em seguida pela Bolívia, Argentina e Uruguai. A divulgação da pedagogia de Decroly aconteceu, em grande parte, graças a colaboradores como "Amélia Hamaïde, Geraldo Boon, L. Dalhem, Mlle. Deschamps e Mlle. Monchamp” (LOURENÇO FILHO, 1930, p. 133).

\section{Os centros de interesse na escola: Abner de Moura (1931)}

O livro intitulado "Os Centros de Interesse na Escola" apresenta sugestões para lições globalizadas, segundo o sistema proposto por Ovide Decroly, como constituição a uma escola brasileira renovada, escrito pelo Professor Abner de Moura (Diretor do grupo escolar de Angatuba do estado de São Paulo). Esse livro foi organizado pela Biblioteca de Educação, sob direção de Lourenço Filho e publicado pela Companhia Melhoramentos de São Paulo em novembro de 1931.

No primeiro capítulo do livro, “Os Centros de Interesse na Escola”, Moura (1931, p. 7) exibe a vida e obra de Decroly, destacando que esta obra sugeria “[...] maneiras de praticar as ideias deste pedagogista, em ambiente brasileiro"; um movimento de apropriação das ideias de Decroly no Brasil. No âmbito pedagógico brasileiro, o ideário de Decroly foi divulgado por Paulo Maranhão (inspetor escolar no Distrito Federal), Maria Luíza de Almeida e Júlio de Oliveira (em Minas Gerais), Moreira de Sousa (no Ceará), Alice Meireles Reis Zuleica Ferreira e Lourenço Filho (em São Paulo).

No segundo capítulo, “O Sistema Decroly”, Moura (1931) expõe detalhadamente a pedagogia de Decroly a partir das ideias centrais da observação, de associação e dos Centros de Interesse. Moura (1931) ressalta que este livro não pretende solucionar o problema de todas as escolas do Estado, entretanto revelaria um ensaio, ainda em evolução, que poderia melhorada dia a dia a prática dos professores. Este livro, conforme aponta o autor, não deverá ser interpretado 


\section{Dialogia}

FERNANDES, Juliana Chiarini Balbino. Os centros de interesse lidos em manuais do ensino primário:

Há saberes aritméticos?

literalmente pelo professor, ao contrário, o sistema Decroly “[...] há de ser interpretado, vivificado pela atividade do professor" (MOURA, 1931, p. 13).

A escola proposta por Decroly preocupava-se com a criança, preparando-a para as exigências sociais, partindo da observação para elaborar um programa síntese, disposto da seguinte forma: Conhecimento, pela criança, de suas necessidades (necessidade de alimentar-se; necessidade de lutar contra as intempéries; necessidade de defender-se contra os perigos e acidentes diversos; necessidade de ação e do trabalho solidário, na renovação constante e da alegria do espírito) e Conhecimento do meio - ambiente humano - familiar, escolar e social; animal e vegetal (ação favorável ou desfavorável do ambiente sobre o indivíduo; a reação do indivíduo sobre o ambiente). Moura (1931, p. 22) apresenta, como exemplo, o programa oficial das escolas de Minas Gerais, conforme é possível observar detalhadamente na Imagem 1.

É possível observar, a partir desse programa de ensino, a criança no centro do processo e a ênfase dada ao cotidiano com a finalidade de criar situações que despertassem a aprendizagem os Centros de Interesse. Nesse ínterim, Moura (1931, p. 28) comenta a dificuldade em atender os diversos níveis de ensino, “[...] os pontos essenciais, não só para desperta a iniciação geral do educando em conhecimentos indispensáveis, como para despertar aptidões, que se conjuguem com as necessidades educativas apontadas pelo século”.

Imagem 1: Programa do $1^{\circ}$ ano da escola de Minas Gerais

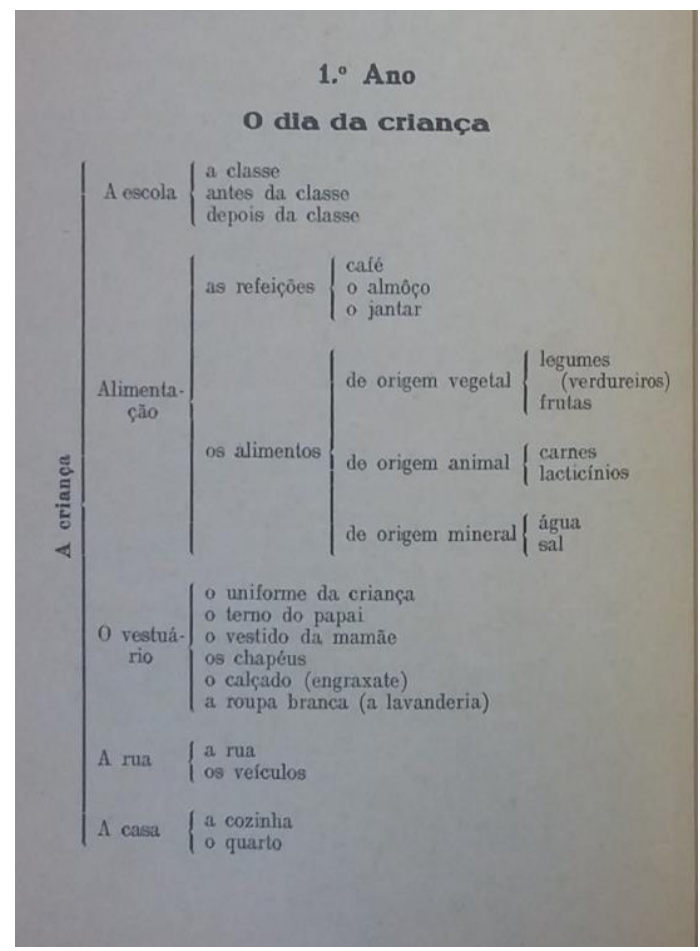

Fonte: Moura (1931, p. 22). 
No capítulo III, "Aplicação", Moura (1931) apresenta a organização dos programas seguindo os conceitos dos Centros de Interesse e como desenvolvê-los. Conforme os estudos de Decroly, os Centros de Interesse deveriam ser trabalhados a partir de três etapas fundamentais, referentes ao tratamento dos assuntos: observação, associação e expressão. Os exercícios de observação deveriam colocar em movimento as demais atividades mentais, formando uma base racional de todos os exercícios. O ato de observar conduz ao de comparar, de modo que, intuitivamente possibilitaria medir, pesar, contar; esses são modelos de exercícios, chamados de satélites, que os professores poderiam utilizar para estimular os alunos em sala de aula (MOURA, 1931).

Após a observação, o aluno seguirá para a associação, etapa que requererá esforço tanto do aluno, quanto do professor. Nesta etapa, será realizada a verificação da experiência de cada aluno e, a partir desta verificação, será dado um valor científico ou cultural ao conhecimento. $\mathrm{Na}$ expressão, segundo Moura (1931, p. 31) compreenderá “[...] tudo o que permite a manifestação do pensamento de modo acessível aos demais".

Esse programa, elaborado por Decroly, contempla e estabelece relações entre as três fases e as matérias da escola, sendo elas:

1) Observação: representa as lições de coisas, as lições elementares de ciências naturais, a geometria, o cálculo.

2) Associação: no espaço e no tempo, substitui a história e a geografia, concebidas, ademais de um ponto de vista mais amplo.

3) Expressão: compreende todos os exercícios de linguagem, incluindo a ortografia, as lições de cor etc., assim também como os chamados trabalhos manuais e o desenho (MOURA, 1931, p. 32-33).

Em específico, o saber aritmético está presente no cálculo e relacionado a outras matérias, presente na "observação", primeiramente sob a forma de exercícios de comparação; depois de medida com unidades naturais; e, por fim, de medidas com unidades convencionais. O ensino de aritmética pode subordinar-se ou não ao Centros de Interesse.

No capítulo IV, "Uma experiência”, expõem-se exemplos de situações de aplicação do Centros de Interesse. Além disso, há o questionamento quanto ao horário do programa proposto por Decroly. Moura (1931, p. 39) explica que “[...] uma escola ativa não poderá nunca se reger por um horário-mosaico, em que os exercícios sejam regulados, em sua extensão, por minutos fatais, e de que o diretor exija o mais rigoroso cumprimento, de relógio, na mão”.

Nesse ponto, Moura (1931) convoca Lourenço Filho para explicar que será preciso abolir o horário por minuto e aderir a um plano de trabalho diário, semanal e flexível que possibilitaria o 


\section{Dialogia}

FERNANDES, Juliana Chiarini Balbino. Os centros de interesse lidos em manuais do ensino primário: Há saberes aritméticos?

desenvolvimento de vários exercícios. Como exemplo desta distribuição de horários, o quadro desenvolvido por Ovide Decroly utilizado na Escola Normal n 5 em Buenos Aires (MOURA, 1931, p. 40), conforme Imagem 2.

Imagem 2: Quadro horário da escola normal n. 5 em Buenos Aires

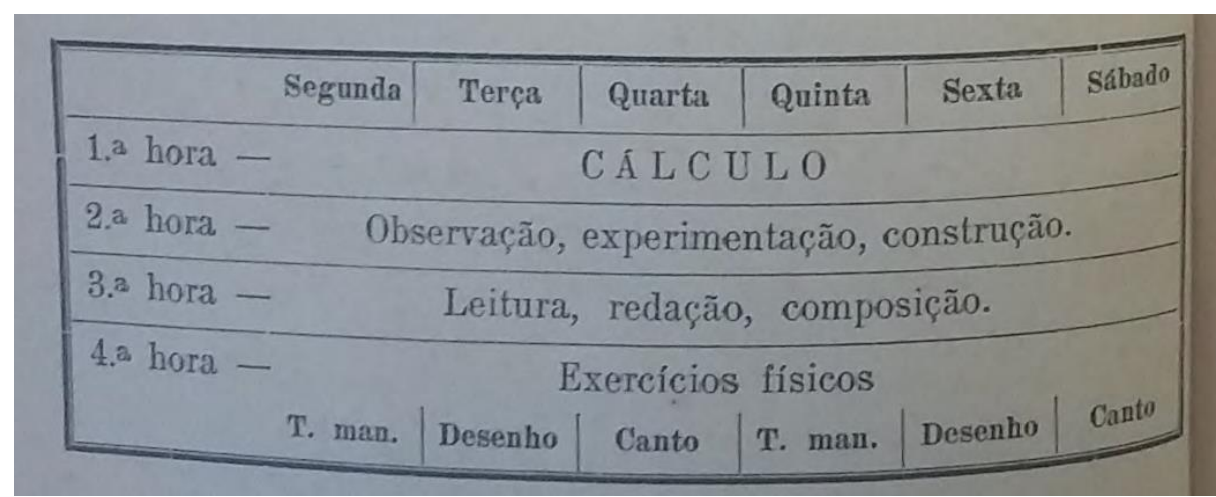

Fonte: Moura (1931, p. 40).

Moura (1931), a partir desse horário de Decroly, aplicou o seguinte horário na Escola Rio Branco: $1^{\mathrm{a}}$ parte (comunicação de material, narrativas, recortes de jornais e revistas, sua classificação, leitura silenciosa ou coletiva); $2^{a}$ parte (exercícios para aplicação de cálculo e trabalhos em grupos); $3^{a}$ parte (trabalho individual livre: caligrafia, cálculo, pesquisa para associação, cadernos de vida); e $4^{a}$ parte (exercícios de expressão, compreendidos o canto, jogos ginásticos, construção, redação e desenho).

No capítulo V, "Planos de Lições", Moura (1931) apresenta sugestões de Planos de Lições a partir dos Centros de Interesse e exemplos de subcentros: os dentes; a cozinha; o fogão; preparo do café; legumes; mandioca; as frutas; a laranja; o tomate; o mamão; o cacau; o vinho; o porco; as formigas; serpentes; as aves; o sabão; couros e peles; as cores; a chácara e a vaca; e coelhos.

Esses Planos de Lições seguem a estruturação proposta por Decroly (observação, associação e expressão). É possível notar a presença dos saberes aritméticos na observação e associação, ao comparar os tamanho e formas de objetos; e associar as quantidades de frutas e legumes. $\mathrm{Na}$ expressão, saberes aritméticos referem-se ao cálculo e à quantidade de objetivos, gêneros alimentícios e/ou animais.

No último capítulo, capítulo VI, "Conclusão", Moura (1931) estava convicto de não apresentar novidades em sua obra, no que se refere à teoria e à prática da Escola Nova.

Este livro tinha por finalidade apresentar um estudo realizado em ambiente brasileiro, em específico, por professores brasileiros que ensaiam as práticas da escola decrolyana. As experiências 
contidas neste livro não eram praticadas e nem observadas em grandes cidades, em meio industrializados; pelo contrário, a prática da escola decrolyana é propícia para o meio agrícola ou para uma cidade pequena de interior.

O intuito da obra também era encorajar os estudos e as experimentações dos professores dispostos a melhorar a escola. Porém, para isso, é necessário “[...] ler, meditar, cotejar os próprios resultados de sua observação com a dos outros” (MOURA, 1931, p. 75). Moura (1931) ressalta que a bibliografia brasileira sobre as experiências da escola decrolyana é escassa, mas é possível encontrar obras em outras línguas, por exemplo, em castelhano, deixa como sugestão alguns títulos de livros em espanhol.

No final deste livro consta um "Apêndice" onde Moura (1931) exibe uma adaptação das lições do programa Decroly para uma classe de primeiro ano, na Escola Rio Branco, em São Paulo, em 1928. O primeiro exemplo de Centros de Interesse proposto foi "A criança e a escola", em que específico os saberes aritméticos estão evidenciados na observação, para a medida ou cálculo, podendo estar representados em exercícios envolvendo: números e medidas (fazer contar, uma por uma, as portas, as janelas, as lâmpadas, as figuras da sala ou outros objetos); decomposição numérica (quatro tem dois e dois); compor (dois e dois, quatro); e expressão escrita desses cálculos por meio de tracinhos ou pontinhos.

Um subcentro proposto, “A casa do aluno”, destaca-se na observação os cômodos da casa, diferentes formatos de telha, cor. $\mathrm{Na}$ Associação, comparação com as casas vizinhas; com a cada da escola; a casa da fazenda, a casa dos índios. Na Expressão, há divisão em: desenho, leitura, cartonagem e números e medidas. Os saberes aritméticos presentes números e medidas: servindose da casa construída onde serão desenhadas as janelas, portas; e escritas de números, até 3 ou 4.

\section{Considerações}

Retomando o objetivo deste artigo, analisar a presença os saberes aritméticos no manual didático "Os Centros de Interesse na Escola” (1931) a partir das apropriações do ideário de Ovide Decroly, é possível identificar apropriações do ideário decrolyano e saberes aritméticos presentes nesta obra.

No que se refere a apropriação, o manual faz referência a Lourenço Filho, um dos responsáveis por divulgar o ideário da Escola Nova no Brasil. Em sua obra, Introdução a Escola Nova, Lourenço Filho exibe um capítulo destinado aos “Centros de Interesse de Decroly" e Moura referência em seu livro esse capítulo. 
Corroborando com os indícios de apropriação, Moura (1931) expõe os personagens que divulgaram a proposta Centros de Interesse no Brasil, sendo eles: Paulo Maranhão (inspetor escolar no Distrito Federal), Maria Luíza de Almeida e Júlio de Oliveira (em Minas Gerais), Moreira de Sousa (no Ceará), Alice Meireles Reis Zuleica Ferreira e Lourenço Filho (em São Paulo); destacase, novamente, o nome de Lourenço Filho, entre esses nomes.

No segundo movimento de análise deste manual, especificamente relacionado com os saberes aritméticos, observa-se que esses saberes estão relacionados com: noção de número, contagem numérica, dobro, metade, leitura e escrita dos números, medida, figuras geométricas, comparações e situações problemas.

No capítulo V, Moura (1931) apresenta sugestões de Planos de Lições a partir dos Centros de Interesses. Nesses planos é possível notar a presença dos saberes aritméticos ao comparar os tamanho e formas de objetos; e associar as quantidades de frutas e legumes. Na expressão, saberes aritméticos referem-se ao cálculo e quantidade de objetivos.

Outro ponto de destaque neste manual é o "Apêndice", onde é exibido aos professores uma sugestão de Planos de Lição de Centros de Interesse que, de certa forma, auxiliaria os professores em sala de aula. Esse é um primeiro movimento de apropriação dos Centros de Interesse de torná-lo aplicável aos professores brasileiros (como um exemplo).

Esse apêndice é uma adaptação das lições iniciais do programa Decroly de 1928, destinado para uma classe de primeiro grau, da Escola Rio Branco de São Paulo, de 1928; ano de destaque dos Centros de Interesse em Minas Gerais. Nesse ponto, estendem-se os cuidados e olhares para a formação profissional e nascem rubricas específicas, neste caso, os Centros de Interesse. Quando, no manual de Moura, é apresentado o apêndice aos professores, é possível observar a articulação entre os saberes a ensinar e para ensinar.

Uma inquietação que surgiu durante o estudo sobre Centros de Interesse e que, a partir da análise desse manual foi possível compreender, refere-se à divisão das matérias em sala de aula. Inferiu-se que o professor deverá abolir o horário por minuto, mas que será necessário um plano de trabalho diário, o qual permitirá, ao professor, o desenvolvimento de vários exercícios. Moura (1931) apresenta um exemplo de distribuição: na primeira hora de aula, o Cálculo deve ser priorizado; na segunda hora de aula, a observação, experimentação e construção; na terceira hora de aula, leitura, redação e composição; e, na quarta hora de aula, exercícios físicos (trabalhos manuais, desenho e canto). 


\section{Dialogia}

FERNANDES, Juliana Chiarini Balbino. Os centros de interesse lidos em manuais do ensino primário:

\section{Referências}

CHARTIER, R. O mundo como representação. Estudos avançados. IEA-USP. São Paulo, 1991.

BORER, V. L. Les savoirs: un enjeu crucial de l'institutionnalisation des formations à l'enseignement. In: Rita Hofstetter et al. Savoirs en(trans)formation - Au coeur des professions de l'enseignement et de la formation. Bruxelles: Éditions De Boeck Université, 2009, p. 41-58.

HOFSTETTER, R.; SCHNEUWLY, B. Introduction. In: HOFSTETTER, R. et al. Savoirs en (trans)formation - Au coeur des professions de l'enseignement et de la formation. Bruxelles: Éditions De Boeck Université, 2009. p. 7-40.

LOURENÇO FILHO, M. B. Introducção ao estudo da Escola Nova. Bibliotheca de Educação, vol. XI. Companhia Melhoramentos de São Paulo, 1930.

MOURA, A. Os centros de Interesse na Escola. Companhia Melhoramentos de São Paulo. São Paulo, 1931.

VALENTE, W. R. et al. A matemática na formação de professores e no ensino: processos e dinâmicas de produção de um saber profissional, 1890-1990. Projeto de Pesquisa. São Paulo: FAPESP. 2017. Disponível em: http://bv.fapesp.br/pt/auxilios/98879/amatematica-naformacao-de-professores-e-no-ensino-processos-e-dinamicas-de-producao-deum-saberp/?q=17/15751-2. Acesso em: 28 jun. 2019. 